\title{
Effects of shot peening and artificial surface defects on fatigue properties of $50 \mathrm{CrV} 4$ steel
}

\author{
Nursen Saklakoglu ${ }^{1} \cdot$ Amir Bolouri $^{2}$ (I) $\cdot$ Simge Gencalp Irizalp ${ }^{1} \cdot$ Fatih Baris $^{1} \cdot$ Ali Elmas $^{3}$
}

Received: 2 August 2020 / Accepted: 15 December 2020 / Published online: 11 January 2021

(C) The Author(s) 2021

\begin{abstract}
Shot peening processes are commonly used for improving the fatigue properties of steels. Shot peening introduces a compressive residual stress field in the near surface of steel, which can reduce or stop the growth of fatigue cracks and improve fatigue properties. This study experimentally investigated the effect of shot peening on the fatigue properties of $50 \mathrm{CrV} 4$ steel alloys with different artificial surface defects. Drilling tools were used to introduce different artificial defects with root radii of $0.585 \mathrm{~mm}$ and $0.895 \mathrm{~mm}$ on the surface of unpeened samples. The shot peening was applied to the drilled and undrilled samples. Scanning electron microscopy (SEM) observations, micro-hardness and X-ray diffraction residual stress measurements were conducted to analyse the characteristics of the shot-peened and unpeened samples. The results show that the shot peening leads to the transformation of the retained austenite to martensite in the near-surface microstructure. The hardness rates of the surface and near surface both increase by $8 \%$ after the shot peening. The peened samples exhibit compressive residual stresses with a high degree of isotropy in the near surface. The fatigue properties of samples were experimentally evaluated by conducting 3-point bending tests. The results indicate that the shot peening improves the fatigue life of drilled and undrilled samples. For the defects with the root radius of $0.895 \mathrm{~mm}$, the shot peening leads to a $500 \%$ improvement in the fatigue life compared to unpeened samples regardless of defect depth. For the defects with the root radius of $0.585 \mathrm{~mm}$, the improvement in fatigue life is $40 \%$ for the defect depth of $0.2 \mathrm{~mm}$ compared to unpeened samples. The improvement increases to $60 \%$ and $200 \%$ by increasing the defect depths to $0.4 \mathrm{~mm}$ and $0.6 \mathrm{~mm}$. The fatigue properties are linked to the changes in the features of defects mainly caused by the deformation hardening and compressive residual stress after shot peening.
\end{abstract}

Keywords Fatigue life $\cdot 50 \mathrm{CrV} 4$ steel $\cdot$ Shot peening $\cdot$ Artificial defect

Amir Bolouri

amir.bolouri@uwe.ac.uk

Nursen Saklakoglu

nursen.saklakoglu@cbu.edu.tr

Simge Gencalp Irizalp

simge.gencalp@cbu.edu.tr

Fatih Baris

fthbrs@yahoo.com

Ali Elmas

alielmas.ae@gmail.com

1 Department of Mechanical Engineering, Manisa Celal Bayar University, 45140 Muradiye, Manisa, Turkey

2 Department of Engineering, Design and Mathematics, University of the West of England, Bristol BS16 1QY, UK

3 Donmez Clutch, A.O.S.B., 10039 Sk. No. 2, 35620 İzmir, Çiğli, Turkey

\section{Introduction}

High-strength 50CrV4 steel alloys are widely used for loadbearing applications where both toughness and resistance to abrasion are key requirements, including gears, pinions, shafts and axles [1]. Small surface defects and scratches can be produced due to manufacturing processes such as casting, forging and welding, installation and foreign object damages during the service. When these parts are subjected to cyclic stresses at high loads, fatigue cracks can initiate and propagate from these surface defects [2,3]. Moreover, the micro-cracks, voids and porosities that tend to grow during cyclic loading decrease their fatigue resistance [4]. For high-strength steel alloys, these defects increase the probability of fatigue failure at very-high-cycle fatigue (VHCF) regimes [2, 3]. However, when stress is below the fatigue limit, these defects are rarely the origins of crack propagation and may become nonpropagating cracks [5]. Metallurgical defects such as 
inclusions can act as stress raisers and initiate fatigue cracks in VHCF regimes below the fatigue limit [6].

The effects of small surface defects on the fatigue properties have been extensively studied for metals [7-10]. It is generally concluded that the fatigue strength depends on the size and characteristics of the defects. For example, the defects up to a size of approximately $50 \mu \mathrm{m}$ do not decreasecompared to a defect-free material-the fatigue strength of mild steels [9], while non-metallic inclusions with a size of a few microns can be detrimental to high-strength steels [11]. When a scratched metal is subjected to the bending fatigue cycle, the performance is mainly governed by the root radius of the scratch [12]. Recent studies have explored to understand the effects of interaction between defects [13, 14], the mean applied load [15] and loading conditions [16] on the fatigue life in the presence of surface defects. Other microstructural discontinuities such as micro-shrinkage cavities frequently cause not only significant deterioration but also large scatter in fatigue strength [17]. Therefore, the ability to understand the negative effects of those defects on the fatigue life and prevent them is crucial in engineering design [16].

Surface treatments that generate compression-type residual stresses are ideal for improving the fatigue life of the treated parts [18]. Shot peening processes have been used to effectively improve fatigue strength of steel alloys $[19,20]$. It has been shown that the fatigue life can be improved by 600 $1500 \%$, when an appropriate shot peening process has been employed for high-strength steel alloys [21]. Shot peening also leads to changes in material's microstructures, surface morphology and the isotropy of mechanical properties [20]. Shot peening includes the flowing of balls with high kinetic energy to induce a plastic deformation and a compressive residual stress in the near surface [22]. The compressive residual stress counteracts the tensile stress due to the mechanical cycle loads and improves the fatigue properties of materials $[19,23]$. However, the improvement in the fatigue life depends on the surface quality of a component after shot peening $[7,24]$ as it changes surface topography [25]. It has been shown that when a scratch of a certain size is produced on the surface of a shot-peened component, the benefit of shot peening on the fatigue properties can be reduced or even completely eliminated depending on scratch size [26, 27]. Jiwang Zhang et al. [19] studied the EA4T axle steel specimens which were subjected to micro-shot peening and then artificial defects were introduced in the specimens. They found that the critical defect sizes with no negative effect on fatigue strength were $60 \mu \mathrm{m}$ and 70 for unpeened and shotpeened specimens, respectively. A. Turnbull et al. [28] showed that a significant benefit of shot peening on the fatigue life of steam turbine blade steel is still retained even for corrosion pits with depth of about $300 \mu \mathrm{m}$.

It is widely accepted that if surface defects are rendered harmless through shot peening and the fatigue limits of such materials improve, a marked improvement in component reliability and a decrease in costs can be achieved. There have been few studies regarding the effects of shot peening on materials containing an original surface defect. More recently, it has been pointed out that the bending fatigue limit of highstrength steel specimens containing a small drilled hole [29, 30] or a semi-circular slit [31] can be increased by shot peening. The small defects with a depth of less than $0.1 \mathrm{~mm}$ for drilled holes and $0.15 \mathrm{~mm}$ for circular slit can be rendered harmless on the bending fatigue limit. However, the effects of shot peening on the fatigue properties of samples containing different types and sizes of surface defects are unclear. This study aims to provide insight into the possibility of using the shot peening process to repair damaged components with surface defects. In this study, artificial defects with different dimensions and root radii were introduced on the surface of the $50 \mathrm{CrV} 4$ steel. The 3-point fatigue bending tests with both asreceived and artificially defected samples were performed. The defected samples were shot-peened. Subsequently, their fatigue properties were evaluated and compared with unpeened samples.

\section{Experimental procedure}

The material used in this study was $50 \mathrm{CrV} 4$ steel alloy with the chemical composition shown in Table 1. The mechanical properties of as-received material are listed in Table 2. The average of three tensile tests was evaluated, and Table 2 contains both test results and their mean. Samples were machined for fatigue testing. Figure 1 shows the shape and dimensions of a 3-point fatigue test sample. After the machining, the samples were austenised at $900{ }^{\circ} \mathrm{C}$ for $10 \mathrm{~min}$ followed by oil quenching with $25 \mathrm{~m}^{2} / \mathrm{s}$ viscosity at $40{ }^{\circ} \mathrm{C}$. Then, they were tempered at $400{ }^{\circ} \mathrm{C}$ for $180 \mathrm{~min}$. After heat treatment, artificial surface defects (drill holes) with different sizes were created using two different drilling tools in the middle of the samples. Details of the defects are shown in Table 3. It is worth mentioning that defect diameter $(d)$ is the diameter of the hole on the surface of samples created using drilling bit. Shot peening was applied to drilled and undrilled samples. Table 4 shows the shot peening conditions in this study. After heat treatment, all samples were slightly polished to remove scales. The average roughness (Ra) was $0.22 \mu \mathrm{m}$ while it was $2.5 \mu \mathrm{m}$ after shot peening. Almen intensity was $10 \mathrm{~A}$ and A type plates were used. The shot-peened surface coverage reached $98 \%$, so the surface has been fully covered.

A standard Vickers indenter (Future-Tech FM-700) with an indentation load of $50 \mathrm{~g}$ with 10-s hold at the maximum load was used. The micro-hardness distribution in depth of the shot peening affected layer near the sample surface was measured on the cross-sections and compared with unpeened material. 
Table 1 Chemical composition of $50 \mathrm{CrV} 4$

\begin{tabular}{lllllll}
\hline $\mathrm{C}$ & $\mathrm{Si}$ & $\mathrm{Mn}$ & $\mathrm{P}$ & $\mathrm{S}$ & $\mathrm{Cr}$ & $\mathrm{V}$ \\
\hline $0.47-0.55$ & Max 0.4 & $0.70-1.1$ & Max 0.035 & Max 0.030 & $0.90-1.20$ & $0.10-0.20$ \\
\hline
\end{tabular}

Scanning electron microscopy (SEM) examinations were carried out to observe the change in surface characteristics due to shot peening using Carl Zeiss 300VP. The phases were identified by the X-ray diffraction analysis using a Panalytical Empyrean XRD diffractometer. The microhardness distribution was obtained along the longitudinal profile using a FM Future-Tech Vickers hardness device.

The magnitude and distribution of surface residual stresses were investigated by the $\sin ^{2} \Psi$ method [32]. The $\Psi$ is the angle between the normal of the surface and the normal of the diffraction plane. The sample was tilted at angles $\Psi=0^{\circ}, \pm 17^{\circ}, \pm$ $24^{\circ}, \pm 30^{\circ}, \pm 35^{\circ}, \pm 40^{\circ}$ and $\pm 45^{\circ}$ during X-ray diffraction residual stress analysis. For the stress calculation, Young's modulus $E=210 \mathrm{MPa}$ and the Poisson's ratio $\nu=0.3$. Cr$\mathrm{K} \alpha$ was used as the X-ray source. Measurements were made in the diffraction lattice plane (211). The Bragg angle was $156.11^{\circ}$. Surface residual stress measurements were performed at different orientations of $\Phi=0^{\circ}, 45^{\circ}$ and $90^{\circ}$ at the same location. Moreover, surface principal residual stresses were calculated for unpeened and shot-peened samples.

The fatigue tests were performed using a $20-\mathrm{kN}$ Sincoteck 3-bending fatigue machine with a Power Swing Mot highfrequency resonator at room temperature at $45-\mathrm{Hz}$ frequency. The stress ratio was $R=0$. The specimens were fatigued at constant maximum stress until failure. The stress amplitudes were $50-75 \%$ of $0.2 \%$ offset yield strength.

\section{Results and discussion}

\subsection{Micro-hardness profile}

Figure 2 shows the micro-hardness distribution along the thickness of heat-treated samples before and after shot peening. The micro-hardness values for as-received samples are shown for the comparison. It is evident that shot peeing increases the surface hardness of samples. However, the surface harnesses of heat-treated peened and unpeened samples were lower compared to the hardness of the core of the samples. The loss of hardness on the surface of the samples was due to decarburisation that occurred during the heat treatment. It is worth noting that unlike defects such as flaws, scratches and inclusions, the decarburisation is not the origin of stress concentration. However, it decreases the surface hardness and has the deleterious effect on the fatigue strength [33]. As it can be seen in Fig. 2, the shot peening recovers some degree of hardness loss due to the decarburisation. When the shot peeing was applied, the surface and near-surface hardness increased by $\sim 8 \%$ compared to unpeened samples.

\subsection{Microstructural characteristics}

Figure 3 shows near-surface microstructures for shot-peened and unpeened samples. For unpeened samples, the nearsurface microstructure contains a large amount of the retained austenite. The retained austenite is detectable as shiny white islands (Fig. 3b), in sharp contrast to light black plate-shaped martensite plates. The near-surface microstructure of the peened samples shows that the amount of retained austenite decreases. In addition, with the shot peening, it appears that the morphology of the retained austenite changes due to the breakage or the reunion of the retained austenite induced by deformation. The decrease in the amount of retained austenite after shot peening can be a result of the strain-induced martensite transformation. This is a phase transformation that can occur by the severe plastic deformation after shot peening. The strain-induced martensite derives from the transformation of austenite into body centred tetragonal ( $\alpha^{\prime}$-martensite). The transformation to strain-induced martensite from the retained austenite will benefit fatigue strength as the martensite is a harder phase compared to the austenite [34].

Figure 4a shows XRD results for near-surface unpeened samples. It shows a pattern of martensite, which appears to have peak positions similar to the $\alpha$-Fe phase. In addition, the peaks of the $\gamma$-Fe phase indicate the presence of retained austenite. The XRD results for near-surface shot-peened samples

Table 2 Mechanical properties of as-received material

\begin{tabular}{lllll}
\hline $\begin{array}{l}\text { Sample } \\
\text { no. }\end{array}$ & $\begin{array}{l}\text { Yield strength } \\
(\mathrm{MPa})\end{array}$ & $\begin{array}{l}\text { Avr. yield strength } \\
(\mathrm{MPa})\end{array}$ & $\begin{array}{l}\text { Tensile strength } \\
(\mathrm{MPa})\end{array}$ & $\begin{array}{l}\text { Avr. tensile strength } \\
(\mathrm{MPa})\end{array}$ \\
\hline 1 & 1256 & 1262 & 1332 & $\begin{array}{l}\text { Elongation } \\
(\%)\end{array}$ \\
2 & 1216 & & 1314 & 21 \\
3 & 1314 & & 1381 & 21 \\
\hline
\end{tabular}


Fig. 1 The shape and dimensions of a 3-point fatigue test specimen (dimensions are in $\mathrm{mm}$ )

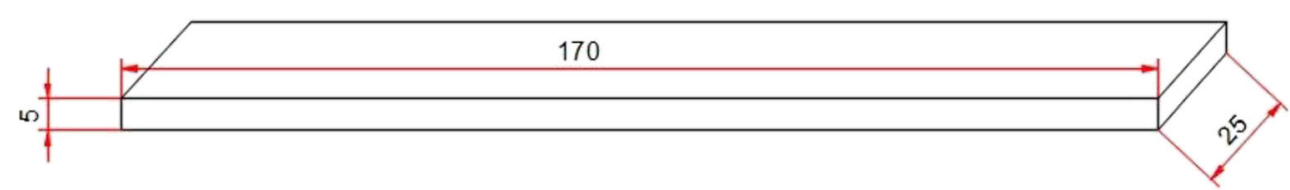

are shown in Fig. 4b. It can be clearly seen that the shot peening process reduces the number of $\gamma$-Fe peaks. These results clearly show that shot peening reduces the retained austenite phases. The microstructural observations in Fig. 3 support this discussion. AlMangour and Yang obtained high compressive residual stress, microstrain, and grain refinement at the shot-peened 17-4 stainless steel component surface which was produced by direct metal laser sintering. The authors revealed that the shot peening generated an austenite-tomartensite transformation via severe plastic deformation [35].

\subsection{Residual stress}

The biaxial surface stress field is defined by the principal stresses, $\sigma_{1}$ and $\sigma_{2}$, with no stress normal to the surface. The stress to be determined is the stress, $\sigma_{\varphi}$, tending in the plane of the surface at an angle, $\varphi$, to the maximum principal stress, $\sigma_{1}$ $[36,37]$. As it is known, the direction of measurement is determined by the diffraction plane. In this research, the stress in any direction (for $0,45,90$ ) was determined by rotating the specimen in the X-ray beam. According to residual stress measurement theory, if the stress is measured in at least three different directions, the principal stresses and their orientation can be calculated [37]. In this study, the surface principal stresses were also calculated for unpeened and shot-peened samples. Table 5 shows surface residual stress measurements at $\phi=0^{\circ}, 45^{\circ}$ and $90^{\circ}$ directions for the near surface of unpeened and shot-peened samples and also surface principal stresses. For unpeened samples, the directions of $\phi=0^{\circ}$ and $90^{\circ}$ exhibit the compressive residual stresses of -20 and $198 \mathrm{MPa}$, respectively. However, the direction of $\phi=45^{\circ}$ shows a tensile residual stress of $117 \mathrm{MPa}$. For these samples, the residual stresses vary largely between $117 \mathrm{MPa}$ and $198 \mathrm{MPa}$ indicating a large amount of anisotropy. For shotpeened samples, compressive residual stresses are identified in all directions, which slightly vary between a maximum of -
$501 \pm 10 \mathrm{MPa}\left(\right.$ at $\phi=45^{\circ}$ ) and a minimum of $-470 \pm 7 \mathrm{MPa}$ (at $\phi=0^{\circ}$ ). These results show that a significant amount of compressive residual stress is introduced into the samples through the shot peeing process. In addition, the small difference in the residual stresses at different directions indicates that the shot-peened samples possess a high degree of isotropy in microstructures and properties.

\subsection{Fatigue properties}

Figure 5 shows the effect of shot peening on the fatigue life of undrilled samples. For these samples, the shot peening considerably increases the fatigue life by $800 \%$ at the fatigue stress of $672 \mathrm{MPa}$. As discussed in Section 3.3, the shot peening creates the near-surface compressive residual stress field that increases the threshold of the crack initiation during fatigue. This reduces the probability of fatigue crack initiation, thus extending the service life of the component [38-40]. For the microscopic cracks already established in the materials, the compressive stress field has the ability to arrest small cracks that initiate at the surface and may lead to a nonpropagating crack [41, 42]. Furthermore, the plastic deformation increases the dislocation density in the near-surface region, which is purported to hinder dislocation movement, associated with crack initiation [43]. Moreover, investigations show that fatigue crack sources are pushed into the area beneath the hardened layer [44].

Figure 6 shows the effect of different artificial surface defects (drilled holes) and shot peening on the fatigue properties. In general, for the unpeened condition, the samples with the drilled holes exhibit lower fatigue life due to stress concentration in comparison with undrilled samples in Fig. 5. This greatly depends on the size and shape of the drilled holes. By increasing the depth $(h)$ and diameter $(d)$ of the drilled holes, the fatigue life reduces (Fig. 5). It can be assumed that the deep holes result in early crack initiation and the holes with

Table 3 The dimensions of artificial surface defects on the fatigue test samples produced by 2-different cutting tools $(d$. defect diameter; $h$, defect height; $R$, defect curvature)

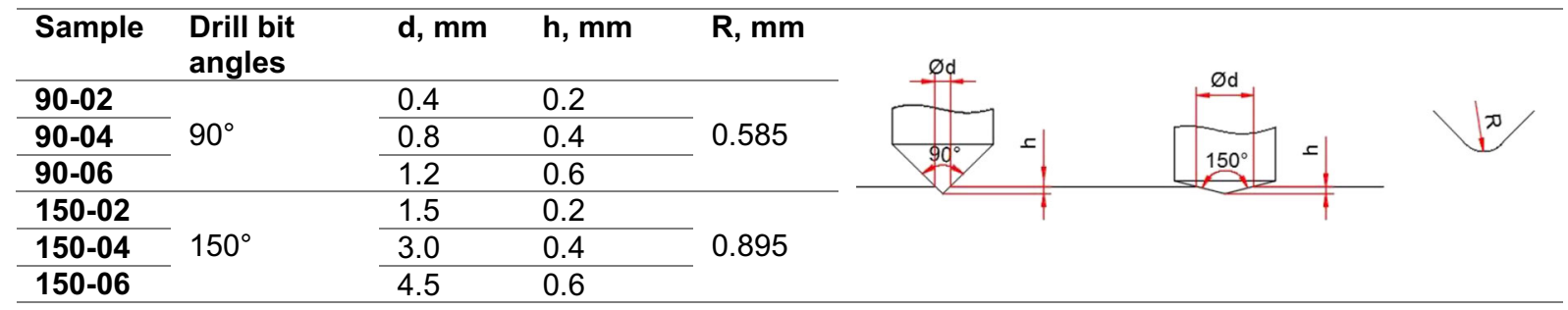


Table 4 The shot peening conditions

\begin{tabular}{ll}
\hline Distance between nozzles and sample & $50 \mathrm{~cm}$ \\
\hline Angle between nozzles and sample & $40^{\circ}$ \\
Ball type & S230 steel (Uniform tempered martensite which has 40 to 51 HRC and nomi size $0.6 \mathrm{~mm})$ \\
Almen intensity & 10 \\
Shot peening time & $30 \mathrm{sec}$ \\
Turbine pressure & $(70-85 \mathrm{psi})$ \\
\hline
\end{tabular}

large diameters create a greater number of nucleation sites along the defect root [45]. Similar observations have been reported for aluminium alloys that increasing the depth and the sharpness of the defect root reduces the fatigue life [4].

The samples drilled using the $90^{\circ}$ drill bit show lower fatigue lives compared to samples drilled using the $150^{\circ}$ drill bit. For example, at the fatigue stress of $624 \mathrm{MPa}$, the samples drilled with the $150^{\circ}$ drill bit at the depth of $0.4 \mathrm{~mm}$ (150-04 samples) had a fatigue life of 231,337 cycles for the unpeened condition, while the fatigue life was 112,550 cycles for $90-04$ samples (the samples drilled with the $90^{\circ}$ drill bit at the depth of $0.4 \mathrm{~mm}$ ). The corresponding losses in the fatigue lives are approximately $30 \%$ and $65 \%$ compared to the undrilled samples with a fatigue life of 320,600 cycles. The holes created by the $150^{\circ}$ drill bit have considerably larger diameters $(d)$ and surface areas compared to holes created by the $90^{\circ}$ drill bit. For example, with a same depth of $0.4 \mathrm{~mm}$, the diameter $(d)$ of hole is $3 \mathrm{~mm}$ for the $150^{\circ}$ drill bit, while it is $0.8 \mathrm{~mm}$ for the $90^{\circ}$ drill bit (Table 3). This may suggest that the holes created with the $150^{\circ}$ drill bit have a larger surface area for cracks to initiate. However, as discussed, there is more loss in fatigue life for specimens drilled with the $90^{\circ}$ drill bit. This is due to the fact that the holes created by the $90^{\circ}$ drill bit are much sharper with the root radius of $0.585 \mathrm{~mm}$ compared to the ones created by the $150^{\circ}$ drill bit with the radius of $0.895 \mathrm{~mm}$. The reduction in the root radius increases the stress concentration factor

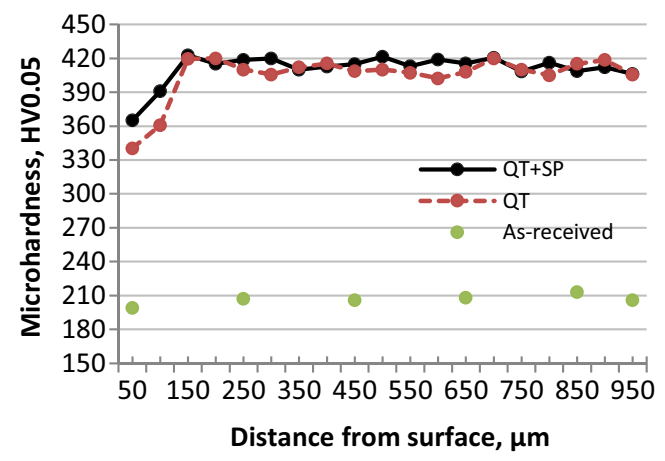

Fig. 2 The micro-hardness distribution of samples that dramatically reduces the fatigue life [46]. Furthermore, the transition from elastic to plastic state of the material is significantly affected by the root radius size of a defect [47]. This is due to the inelastic behaviour of the local strains at the root radius of the defect. Accordingly, when the radius size decreases (that means the sharpness increases) the transition to a plastic state becomes faster and requires a smaller number of cycles. Therefore, it can be concluded that a sharp defect is more detrimental to fatigue life compared to a large defect (with a large surface area), but less sharp.

It can be seen in Fig. 6 that the shot peening improves the fatigue life for the artificially defected samples. For the samples with $150^{\circ}$ holes (Fig. 6a), this improvement is remarkable with $\sim 500 \%$ increase in the fatigue life at the fatigue stress of $672 \mathrm{MPa}$. Very importantly, for these samples at all hole depths, the fatigue life is considerably higher $(\sim 280 \%)$ in comparison with the undrilled samples without shot peening in Fig. 5. It seems that the shot peening significantly eliminates the harmful effects of $150^{\circ}$ holes of all depths. For the specimens with the $90^{\circ}$ holes, the shot peening slightly $(\sim 40 \%)$ improves the fatigue life of the holes with $0.2-\mathrm{mm}$ depth at the fatigue stress of $672 \mathrm{MPa}$. The improvement in the fatigue life is more noticeable for the holes with $0.4-\mathrm{mm}$ and $0.6-\mathrm{mm}$ depths with $65 \%$ and $200 \%$ increases compared to unpeened samples. It is worth noting that the shot peening increases the fatigue life of samples with the $90^{\circ}$ holes to the values equivalent to the fatigue life of undrilled samples without any shot peening (as-received material).

Figure 7 shows the features of artificial defects before and after shot peening. The traces of machining are visible on the unpeened samples (Fig. 7a and c). The shot peening introduces some degrees of plastic deformation on the defects. However, the features of deformation at the $90^{\circ}$ and $150^{\circ}$ holes are different. For the $150^{\circ}$ holes, it appears that a large surface area of holes and their roots are fully hit by balls during shot peeing as the traces of machining are significantly eliminated in the holes (Fig. $7 b)$. This is mainly due to the fact that the diameter of the holes $(d=1.5-4.5 \mathrm{~mm}$, Table 3$)$ for all testing conditions is larger than the diameter of the shot peening balls $(0.6$ 
Fig. 3 Near-surface SEM images of $\mathbf{a}, \mathbf{b}$ unpeened sample; $\mathbf{c}, \mathbf{d}$ shot-peened sample
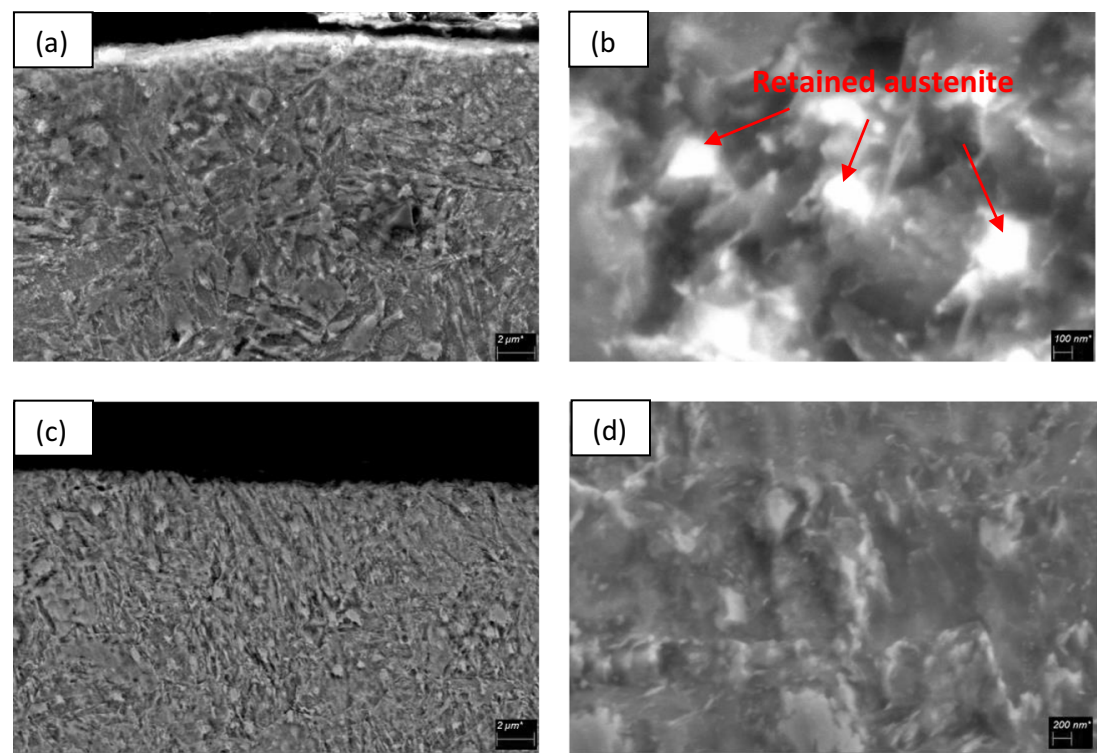

$\mathrm{mm})$. Therefore, it can be expected that the significant amounts of plastic deformation and residual compressive stresses are introduced on the surface of these defects. The beneficial effect of shot peening on the fatigue life of samples with $150^{\circ}$ holes can be clearly seen in the fatigue life of these samples (Fig. 6a), as the increase in the fatigue life is $\sim 500 \%$ compared to the unpeened
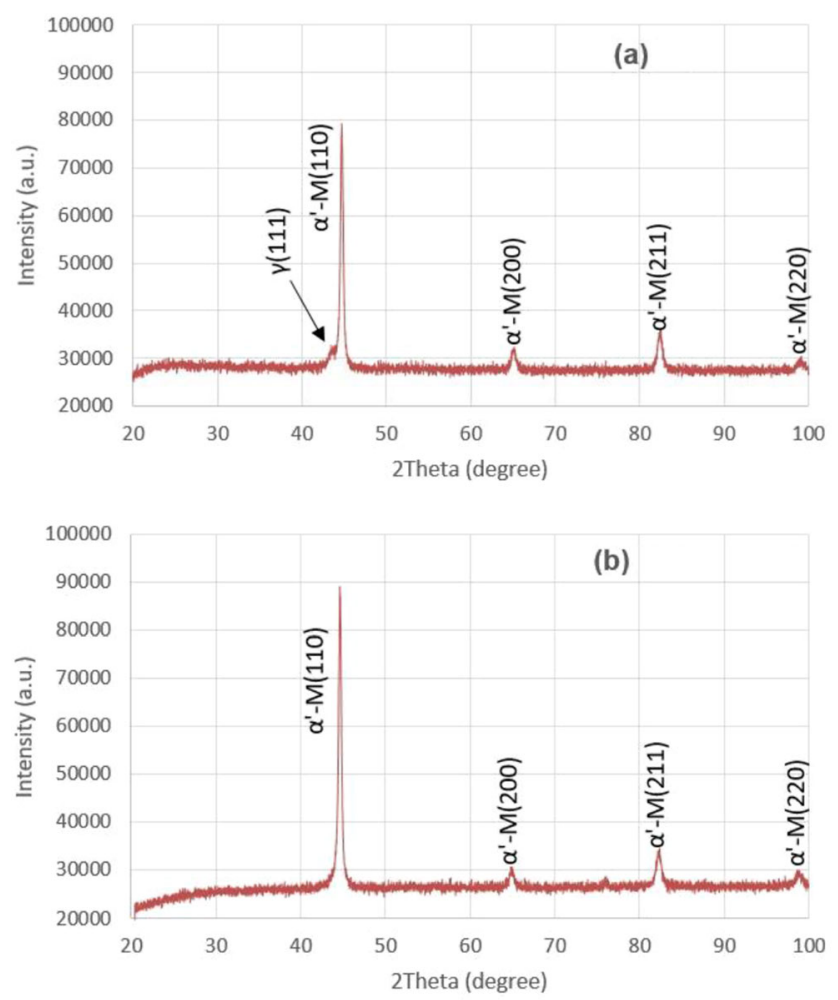

Fig. 4 X-ray diffraction (XRD) patterns of unpeened and shot-peened samples samples. For the $90^{\circ}$ holes, it seems that the surface area of the holes are partially hit by the shot peening balls depending on the diameter of the holes (Fig. 7d, e). For the holes with $0.8 \mathrm{~mm}$ diameter $(0.4 \mathrm{~mm}$ depth, Fig. $7 \mathrm{~d})$, it appears that only the top surface of the holes is hit by balls during the shot peening, which does not effectively introduce the beneficial effect of shot peening on the defects. For these samples, the formation of laps (indicated by arrows) is also observed on the edge of the holes due to plastic deformation. The laps are defined as locations where the material is folded over itself on the surface. The flow of material due to the impact of balls onto the edge of the defects generates lap/fold that has the potential to become harmful for fatigue life [48]. Therefore, the partial ball hits on the surface of the holes and the formation of laps can be responsible for the limited improvement of $40 \%$ and $60 \%$ in the fatigue life of samples containing the $90^{\circ}$ holes with $0.2-\mathrm{mm}$ and $0.4-\mathrm{mm}$ depths, respectively (corresponding to $0.4-\mathrm{mm}$ and $0.8-\mathrm{mm}$ hole diameters, respectively). When the hole depth increases to 0.6

Table 5 Surface residual stress measurements in $0^{\circ}, 45^{\circ}$ and $90^{\circ}$ direction and surface principal residual stress measurements

\begin{tabular}{cll}
\hline & $\begin{array}{l}\text { Residual stresses in any } \\
\text { direction }\end{array}$ & $\begin{array}{l}\text { Principal residual } \\
\text { stresses }\end{array}$ \\
\hline Unpeened (MPa) & $\sigma_{0^{\circ}}=-20 \pm 8$ & $\sigma_{1}=-65$ \\
& $\sigma_{45^{\circ}}=117 \pm 10$ & $\sigma_{2}=-206$ \\
& $\sigma_{90^{\circ}}=-198 \pm 17$ & \\
Shot peened & $\sigma_{0^{\circ}}=-470 \pm 7$ & $\sigma_{1}=-409$ \\
$(\mathrm{MPa})$ & $\sigma_{45^{\circ}}=-501 \pm 10$ & $\sigma_{2}=-711$ \\
& $\sigma_{90^{\circ}}=-487 \pm 8$ & \\
\hline
\end{tabular}




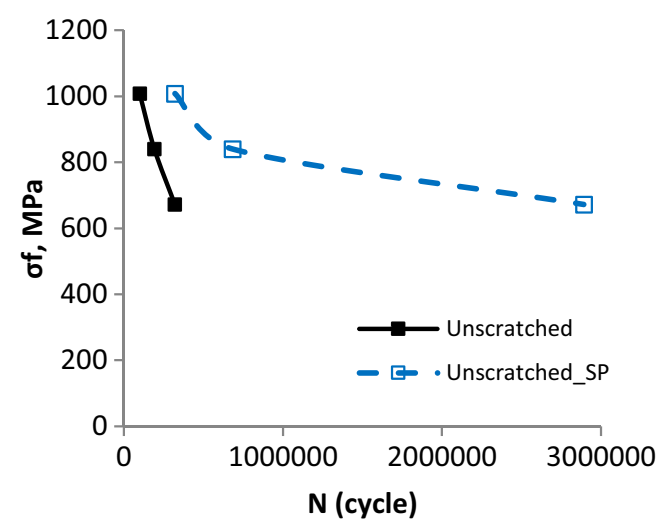

Fig. 5 S-N curves for undrilled specimens with and without shot peening

$\mathrm{mm}$, the hole diameter becomes $1.2 \mathrm{~mm}$, which is larger than the diameter of the shot peening balls $(0.6 \mathrm{~mm})$. Therefore, during shot peening, the balls can hit and cover a larger surface area of the defects. This is reflected in the fatigue life of these samples, as the improvement in the fatigue life is $\sim 200 \%$ compared to unpeened samples. However, the formation of laps for these samples is still visible for these samples (Fig. 7e).

\section{Conclusion}

The surface defects have negative effect on the fatigue properties of components. These defects can be due to manufacturing processes such as machining or during service originated from foreign object damage. This study aims to demonstrate that shot peening can be used to repair these defects and improve their fatigue properties. The effects of shot peening on the fatigue life of
$50 \mathrm{CrV} 4$ steel, containing artificial surface defects of $90^{\circ}$ holes with a root radius of $0.585 \mathrm{~mm}$ and $150^{\circ}$ holes with a root radius of $0.895 \mathrm{~mm}$, were investigated for different hole depths.

- The shot peening increases the surface hardness of $50 \mathrm{CrV} 4$ steel from $340 \mathrm{HV}$ to $365 \mathrm{HV}$. Microstructural characterisations show that the content of retained austenite reduces in the near-surface layers after the shot peening, due to the deformation induced the transformation of retained austenite to martensite. The shot peening produced a significant amount of compressive residual stress in the near surface with a maximum of $-501 \pm$ 10.6 MPa and a high degree of isotropy.

- For the $150^{\circ}$ surface defects, the shot peening significantly improved the fatigue life of samples by $500 \%$ at the fatigue stress of $672 \mathrm{MPa}$ compared to the fatigue life of unpeened samples, regardless of the defect depth.

- For the $90^{\circ}$ surface defects, the improving effect of shot peening on the fatigue life appeared limited, which greatly depended on the depth of the defects. For the $0.2-\mathrm{mm}$ deep defects, the increase in the fatigue life was $\sim 40 \%$, while it was $60 \%$ and $200 \%$ for the $0.4 \mathrm{~mm}$ and $0.6 \mathrm{~mm}$ deep defects for the fatigue stress of $672 \mathrm{MPa}$, respectively. For the samples with the $90^{\circ}$ surface defects, the shot peening improved the fatigue life to values equivalent to the unpeened samples without any artificial defects (asreceived material).

- SEM observations showed that the surface of the $90^{\circ}$ defects was partially hit during the shot peening while a full coverage appeared for the more open $150^{\circ}$ defects. For the $90^{\circ}$ defects, the formation of laps was also observed on the edge of the defects due to the impact of balls.
Fig. 6 S-N curves for drilled samples using $\mathbf{a} 150^{\circ}$ and $\mathbf{b} 90^{\circ}$ drill bits (note the scale of cycles)

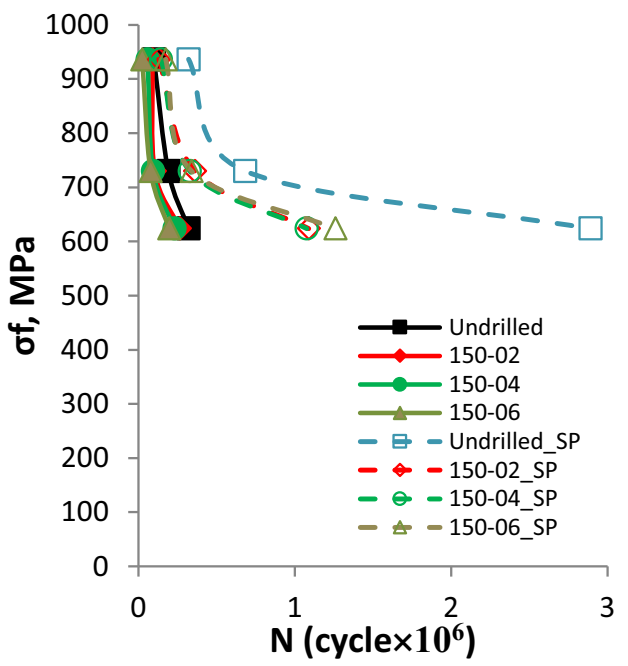

(a)

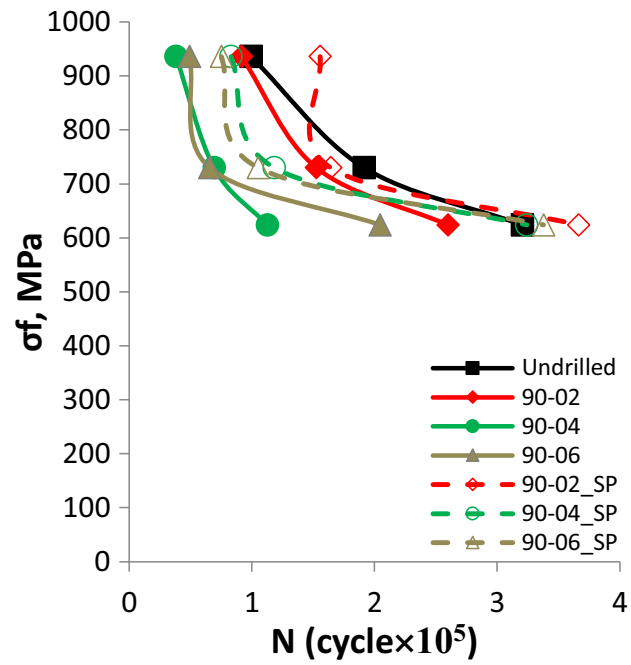

(b) 
Fig. 7 Artificial defects on the fractured surface after fatigue tests a unpeened $150^{\circ}$ and $0.4-$ $\mathrm{mm}$ deep hole; $\mathbf{b}$ shot-peened $150^{\circ}$ and $0.4-\mathrm{mm}$ deep hole; $\mathbf{c}$ unpeened $90^{\circ}$ and $0.6-\mathrm{mm}$ deep hole; d shot-peened $90^{\circ}$ and 0.4 $\mathrm{mm}$ deep hole; e shot-peened $90^{\circ}$ and 0.6-mm deep hole
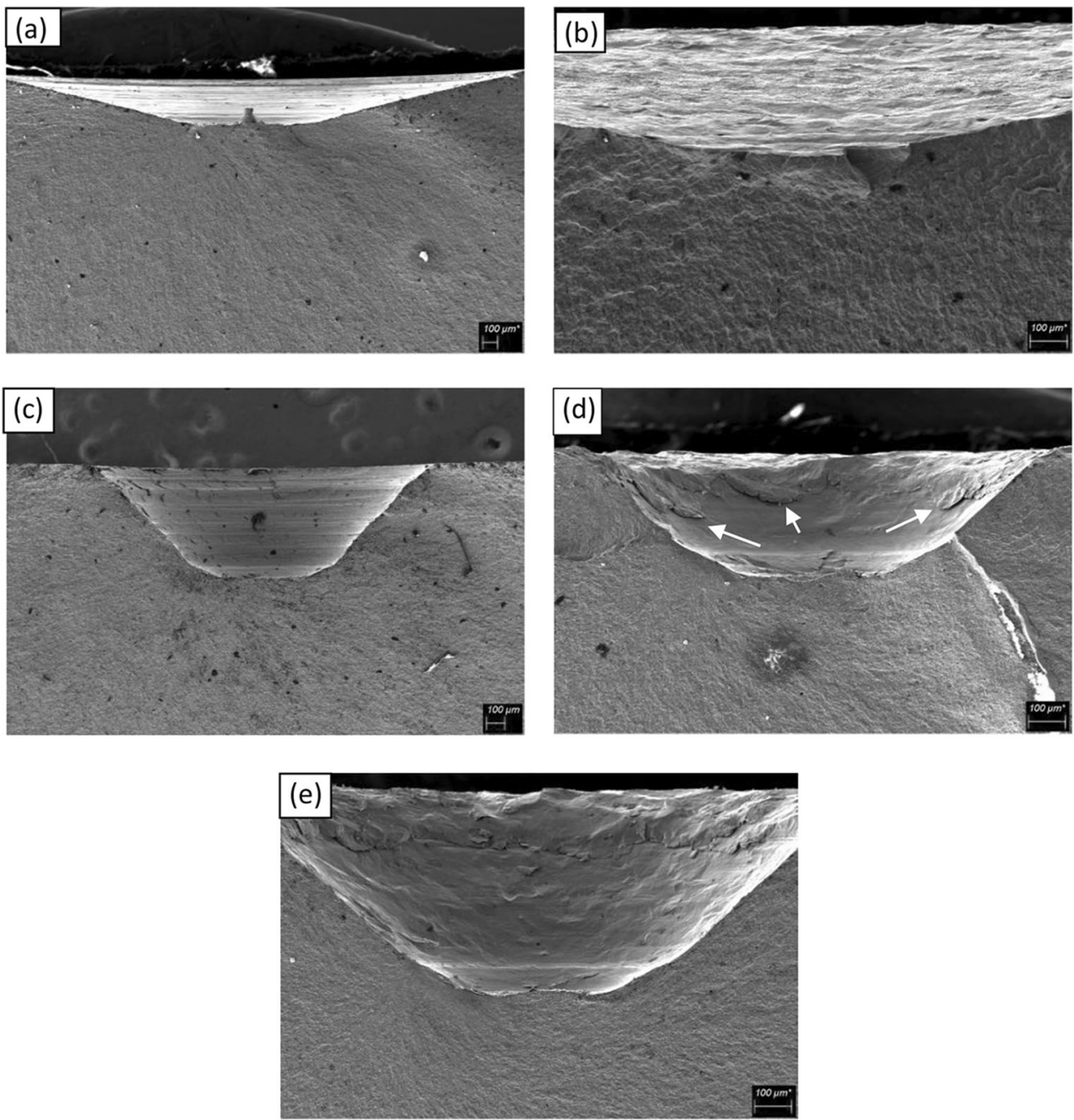

Acknowledgements The authors are thankful to DONMEZ DEBRIYAJ Inc. for providing samples.

Author contributions Nursen Saklakoglu: design of experiments, supervisor to the project, analysing and arranging data, and writing the manuscript; Amir Bolouri: design of experiments, analysing and arranging data, and writing the manuscript; Simge Gencalp Irizalp: reviewing the manuscript, Fatih Baris: conducting experiments, and collecting and analysing data; Ali Elmas: manufacturing samples and advice for industrial application discussion.

Funding This work was financially supported by Celal Bayar University (Project Code: 2018-039) and the University of the West of England through VC Mid-Career fund.

Data availability The raw/processed data required to reproduce these findings cannot be shared at this time. Data will be made available upon request.

\section{Compliance with ethical standards}

Ethical approval There was no ethical issue in this project.

Consent to participate There were no participants in this project.
Consent to publish The authors are the owner of the data in this project and have consent to publish.

Competing interests The authors declare that they have no competing interests.

Open Access This article is licensed under a Creative Commons Attribution 4.0 International License, which permits use, sharing, adaptation, distribution and reproduction in any medium or format, as long as you give appropriate credit to the original author(s) and the source, provide a link to the Creative Commons licence, and indicate if changes were made. The images or other third party material in this article are included in the article's Creative Commons licence, unless indicated otherwise in a credit line to the material. If material is not included in the article's Creative Commons licence and your intended use is not permitted by statutory regulation or exceeds the permitted use, you will need to obtain permission directly from the copyright holder. To view a copy of this licence, visit http://creativecommons.org/licenses/by/4.0/. 
Mater Sci Forum 830-831:139-142. https://doi.org/10.4028/www. scientific.net/msf.830-831.139

2. Nishimura Y, Yanase K, Ikeda Y, Tanaka Y, Miyamoto N, Miyakawa S, Endo M (2018) Fatigue strength of spring steel with small scratches. Fatigue Fract Eng Mater Struct 41:1514-1528. https://doi.org/10.1111/ffe.12793

3. Lin B, Zabeen S, Tong J, Preuss M, Withers PJ (2015) Residual stresses due to foreign object damage in laser-shock peened aerofoils: simulation and measurement. Mech Mater 82:78-90. https:// doi.org/10.1016/j.mechmat.2014.12.001

4. AlMangour B, Yang JM (2017) Integration of heat treatment with shot peening of 17-4 stainless steel fabricated by direct metal laser sintering. JOM. 69:2309-2313. https://doi.org/10.1007/s11837017-2538-9

5. Lai J, Lund T, Rydén K, Gabelli A, Strandell I (2012) The fatigue limit of bearing steels - part I: a pragmatic approach to predict very high cycle fatigue strength. Int J Fatigue 38:155-168. https://oi. org/10.1016/j.ijfatigue.2011.09.015

6. Zimmermann M (2012) Diversity of damage evolution during cyclic loading at very high numbers of cycles. Int Mater Rev 57:7391

7. Tan L, Yao C, Zhang D, Ren J, Zhou Z, Zhang J (2020) Evolution of surface integrity and fatigue properties after milling, polishing, and shot peening of TC17 alloy blades. Int J Fatigue 136:105630. https://doi.org/10.1016/j.ijfatigue.2020.105630

8. Javidi A, Rieger U, Eichlseder W (2008) The effect of machining on the surface integrity and fatigue life. Int J Fatigue 30:2050-2055. https://doi.org/10.1016/j.ijfatigue.2008.01.005

9. Murakami Y (2002) Metal fatigue- effects of small defects and nonmetallic inclusions

10. Schönbauer BM, Mayer H (2019) Effect of small defects on the fatigue strength of martensitic stainless steels. Int J Fatigue 127: 362-375. https://doi.org/10.1016/j.ijfatigue.2019.06.021

11. Karr U, Schuller R, Fitzka M, Schönbauer B, Tran D, Pennings B, Mayer H (2017) Influence of inclusion type on the very high cycle fatigue properties of $18 \mathrm{Ni}$ maraging steel. J Mater Sci 52:5954 5967. https://doi.org/10.1007/s10853-017-0831-1

12. Shingai K (1998) Study on elastic-plastic strain behavior of notched specimen (5. Consideration on fatigue life and cyclic strain behavior of steel under cyclic tensile load). Reports Fac Eng Nagasaki Univ

13. Åman M, Okazaki S, Matsunaga H, Marquis GB, Remes H (2017) Interaction effect of adjacent small defects on the fatigue limit of a medium carbon steel. Fatigue Fract Eng Mater Struct 40:130-144. https://doi.org/10.1111/ffe.12482

14. Åman M, Wada K, Matsunaga H, Remes H, Marquis G (2020) The influence of interacting small defects on the fatigue limits of a pure iron and a bearing steel. Int J Fatigue 135:105560. https://doi.org/ 10.1016/j.ijfatigue.2020.105560

15. Nishimura Y, Yanase K, Tanaka Y, Miyamoto N, Miyakawa S, Endo M (2020) Effects of mean shear stress on the torsional fatigue strength of a spring steel with small scratches. Int J Damage Mech 29:4-18. https://doi.org/10.1177/1056789519831434

16. Yanase K, Endo M (2014) Multiaxial high cycle fatigue threshold with small defects and cracks. Eng Fract Mech 123:182-196. https://doi.org/10.1016/j.engfracmech.2014.03.017

17. Endo M, Yanase K (2014) Effects of small defects, matrix structures and loading conditions on the fatigue strength of ductile cast irons. Theor Appl Fract Mech 69:34 43. https://doi.org/10.1016/j. tafmec.2013.12.005

18. Bag A, Delbergue D, Ajaja J, Bocher P, Lévesque M, Brochu M (2020) Effect of different shot peening conditions on the fatigue life of $300 \mathrm{M}$ steel submitted to high stress amplitudes. Int J Fatigue 130:105274. https://doi.org/10.1016/j.ijfatigue.2019.105274

19. Zhang J, Li H, Yang B, Wu B, Zhu S (2020) Fatigue properties and fatigue strength evaluation of railway axle steel: effect of micro- shot peening and artificial defect. Int J Fatigue 132:105379. https:// doi.org/10.1016/j.ijfatigue.2019.105379

20. Yang S, Zeng W, Yang J (2020) Characterization of shot peening properties and modelling on the fatigue performance of 304 austenitic stainless steel. Int J Fatigue 137:105621. https://doi.org/10. 1016/j.ijfatigue.2020.105621

21. Cláudio RA, Burgess A, Branco CM, Byrne J (2009) Failure analysis of scratch damaged shot peened simulated components at high temperature. Eng Fail Anal 16:1208-1220. https://doi.org/10.1016/ j.engfailanal.2008.07.013

22. Ling FF (2006) Mechanical Engineering Series

23. Webster GA, Ezeilo AN (2001) Residual stress distributions and their influence on fatigue lifetimes. Int J Fatigue 23:375-383. https://doi.org/10.1016/s0142-1123(01)00133-5

24. Li X, Zhang J, Yang B, Zhang J, Wu M, Lu L (2020) Effect of micro-shot peening, conventional shot peening and their combination on fatigue property of EA4T axle steel. J Mater Process Technol 275:116320. https://doi.org/10.1016/j.jmatprotec.2019. 116320

25. Bagherifard S, Ghelichi R, Guagliano M (2012) Numerical and experimental analysis of surface roughness generated by shot peening. Appl Surf Sci 258:6831-6840. https://doi.org/10.1016/j. apsusc.2012.03.111

26. Cláudio RA, Silva JM, Branco CM, Byrne J (2011) A fracture mechanics based approach to predict fatigue life of scratch damaged shot peened components. Procedia Engineering 10:26722677. https://doi.org/10.1016/j.proeng.2011.04.445

27. Claudio RA, Branco CM, Byrne J (2007) Fatigue behaviour of scratch damaged shot peened specimens at elevated temperature. In: Gdoutos EE (ed) Experimental analysis of nano and engineering materials and structures. Springer, Dordrecht. https://doi.org/10. 1007/978-1-4020-6239-1_11

28. Turnbull A, Crocker L, Zhou S (2018) Do corrosion pits eliminate the benefit of shot-peening? Int J Fatigue 116:439-447. https://doi. org/10.1016/j.ijfatigue.2018.07.004

29. Yasuda J, Takahashi K, Okada H (2014) Improvement of fatigue limit by shot peening for high-strength steel containing a crack-like surface defect: Influence of stress ratio. Int J Struct Integr 5:45-59. https://doi.org/10.1108/IJSI-07-2013-0012

30. Takahashi K, Okada H, Ando K (2012) Effects of shot peening on the torsional fatigue limit of high-strength steel containing an artificial surface defect. Int J Struct Integr 3:274-284. https://doi.org/ 10.1108/17579861211264389

31. Takahashi K, Amano T, Ando K, Takahashi F (2011) Improvement of fatigue limit by shot peening for high-strength steel containing a crack-like surface defect. Int J Struct Integr 2:281-292. https://doi. org/10.1108/17579861111162888

32. Gencalp Irizalp S, Saklakoglu N, Akman E, Demir A (2014) Pulsed Nd: YAG laser shock processing effects on mechanical properties of 6061-T6 alloy. Opt Laser Technol 56:273-277. https://doi.org/ 10.1016/j.optlastec.2013.08.011

33. Yamada Y, Kuwabara T (2007) Materials for springs

34. Hassani-Gangaraj SM, Cho KS, Voigt HJL, Guagliano M, Schuh CA (2015) Experimental assessment and simulation of surface nanocrystallization by severe shot peening. Acta Mater 97:105115. https://doi.org/10.1016/j.actamat.2015.06.054

35. AlMangour B, Yang JM (2016) Improving the surface quality and mechanical properties by shot-peening of 17-4 stainless steel fabricated by additive manufacturing. Mater Des 110:914-924. https:// doi.org/10.1016/j.matdes.2016.08.037

36. Prevéy PS (1996) Current applications of XRD diffraction residual stress measurement. Dev Mater Charact Technol ASM Int

37. Prevéy PS (1992) Problems with non-destructive surface x-ray diffraction residual stress measurement. Shot Peen

38. Zhao X, Zhou H, Liu Y (2018) Effect of shot peening on the fatigue properties of nickel-based superalloy GH4169 at high temperature. 
Results Phys 11:452-460. https://doi.org/10.1016/j.rinp.2018.09. 047

39. Schnubel D, Horstmann M, Ventzke V, Riekehr S, Staron P, Fischer T, Huber N (2012) Retardation of fatigue crack growth in aircraft aluminium alloys via laser heating - experimental proof of concept. Mater Sci Eng A 546:8-14. https://doi.org/10.1016/j. msea.2012.02.094

40. Pan X, Li X, Zhou L, Feng X, Luo S, He W (2019) Effect of residual stress on $\mathrm{S}-\mathrm{N}$ curves and fracture morphology of Ti6Al4V titanium alloy after laser shock peening without protective coating. Materials (Basel) 12. https://doi.org/10.3390/ma12223799

41. Zhang J, Wang X, Paddea S, Zhang X (2016) Fatigue crack propagation behaviour in wire+arc additive manufactured Ti-6Al-4 V: Effects of microstructure and residual stress. Mater Des 90:551561. https://doi.org/10.1016/j.matdes.2015.10.141

42. Garcia C, Lotz T, Martinez M, Artemev A, Alderliesten R, Benedictus R (2016) Fatigue crack growth in residual stress fields. Int J Fatigue 87:326-338. https://doi.org/10.1016/j.ijfatigue.2016. 02.020

43. Evans A, Kim SB, Shackleton J, Bruno G, Preuss M, Withers PJ (2005) Relaxation of residual stress in shot peened Udimet $720 \mathrm{Li}$ under high temperature isothermal fatigue. Int J Fatigue 27(10-12): $1530-1534$
44. Gao YK, Lu F, Yin YF, Yao M (2003) Effects of shot peening on fatigue properties of $0 \mathrm{Cr} 13 \mathrm{Ni} 8 \mathrm{Mo} 2 \mathrm{Al}$ steel. Mater Sci Technol 19: 372-374. https://doi.org/10.1179/026708303225010650

45. Newman J, Zerbst U (2003) Engineering fracture mechanics. Eng Fract Mech 70:367-369. https://doi.org/10.1016/s0013-7944(02) 00124-8

46. Uygur I (2011) Notch behavior and fatigue life predictions of discont1 nuously reinforced MMCs. Arch Metall Mater 56. https:// doi.org/10.2478/v10172-011-0012-1

47. Susmel L, Atzori B, Meneghetti G, Taylor D (2011) Notch and mean stress effect in fatigue as phenomena of elasto-plastic inherent multiaxiality. Eng Fract Mech 78:1628-1643. https://doi.org/10. 1016/j.engfracmech.2011.02.011

48. Barrie RL, Gabb TP, Telesman J, Kantzos PT, Prescenzi A, Biles T, Bonacuse PJ (2008) Effectiveness of shot peening in suppressing fatigue cracking at non-metallic inclusions in Udimet ${ }^{\circledR} 720$. Mater Sci Eng A 474:71-81. https://doi.org/10.1016/j.msea.2007.03.100

Publisher's note Springer Nature remains neutral with regard to jurisdictional claims in published maps and institutional affiliations. 